\title{
A systematic review and meta-analysis of weight status among adolescents in Cyprus: scrutinizing the data for the years 2000-2010
}

\author{
Maria G. Grammatikopoulou, ${ }^{1}$ Eleni P. Kotanidou, ${ }^{2}$ Anastasia G. Markaki, ${ }^{3}$ \\ Charilaos Stylianou, ${ }^{4}$ Assimina Galli-Tsinopoulou, ${ }^{2}$ Maria Tsigga, ${ }^{1}$ Maria Hassapidou ${ }^{1}$
}

${ }^{1}$ Department of Nutrition \& Dietetics, Alexander Technological Educational Institute, Thessaloniki; ${ }^{2} 4^{\text {th }}$ Department of Pediatrics, Faculty of Medicine, Aristotle University of Thessaloniki, Papageorgiou General Hospital, Thessaloniki; ${ }^{3}$ Department of Nutrition \& Dietetics, Technological Educational Institute of Crete, Crete; Greece; ${ }^{4}$ Department of Pediatrics, Paphos General Hospital, Anavargos, Paphos, Cyprus

\begin{abstract}
OBJECTIVE: The aim of the present study was to evaluate by pooled and sensitivity analyses all available data on adolescent overweight/obesity in Cyprus. DESIGN: A thorough literature search determined the studies to be examined using Cypriot adolescent samples aged 10-18 years old, with weight status in each sex classified according to the IOTF criteria, published between the years 2001-2011. Eight studies were retrieved, but three fulfilled the criteria for the sensitivity analyses. RESULTS: The pooled prevalence of obesity was $9.8 \%$ in boys $(n=6081)$. The pooled analysis classified $6.1 \%(n=3886)$ of girls as obese, whereas a higher prevalence was observed by the sensitivity analysis $6.4 \%(n=1956, p \leq 0.001)$. The boys' prevalence of overweight was $19.3 \%$ and the girls' $17.1 \%$. Between sexes, boys demonstrated a higher prevalence of obesity and overweight ( $\mathbf{p} \leq \mathbf{0 . 0 0 1}$ for both). The cumulative analyses demonstrated an increase in the prevalence of overweight/obesity until the year 2005 and thereafter a plateauing in boys and a slight decrease in girls in a non-linear manner. CONCLUSION: Approximately 1/3 of adolescent boys and $1 / 4$ of adolescent girls in Cyprus were overweight/obese during the previous decade.
\end{abstract}

Key words: Abdominal obesity, Adolescence, BMI, IOTF, Obese, Obesity, Overweight, Teenagers

\section{INTRODUCTION}

The increased prevalence of childhood obesity in Europe during the last few decades has evolved into an

Address for correspondence:

Maria Hassapidou, Department of Nutrition \& Dietetics, Alexander Technological Educational Institute, Thessaloniki, Sindos P.O. Box 141, GR-57400, Greece;

Tel./Fax: +30 2310 791584; E-mail: mnhass@gmail.com

Received 14-01-2014, Accepted 08-05-2014 important public health issue with epigenetic effects on the health of future adult generations. ${ }^{1}$ However, adolescent obesity is equally important as it represents an age-range closer to adulthood, thus depicting the imminent early adulthood prevalence. In terms of psychology, overweight during adolescence is associated with unhealthy weight-control and disordered eating, actions subvened by the health-risk behavior 
encountered during adolescence. ${ }^{2,3}$ In terms of physiological growth and hormonal response, research has shown that adolescent obesity may disrupt aspects of pubertal development. ${ }^{4}$

Though geographically different from Europe, in Cyprus trends in adolescent obesity appear similar to the rest of the continent. ${ }^{5}$ Several studies have addressed the problem of obesity in Cypriot adolescents and it is acknowledged that a multifaceted public health policy approach is needed in order to combat the disease. ${ }^{6}$ However, the majority of published research includes convenience samples with wide ageranges, often without differentiating between children and adolescents, while the file-drawer problem ${ }^{7}$ (i.e. the non-publication of studies with different results from those expected) impedes understanding of the actual progression of the disease.

The objective of this review of existing data was to synthesize all published information on the weight status of Cypriot adolescents in order to help understand the progression of adolescent obesity and provide data for the development of policies for combating the disease during adolescence.

\section{EXPERIMENTAL METHODS}

\section{Literature search}

We searched Ovid MEDLINE, EMBASE, Google Scholar, Scopus and openarchives.gr for studies published prior to December 2010, using the meSH terms "adolescent OR children", "adolescence OR childhood”, "AND obesity OR overweight”, "AND Cyprus". Where applicable, the search keywords were also translated into the Greek language. In addition, the references cited in each paper were also searched for relevant studies.

\section{Inclusion and exclusion criteria}

Criteria for inclusion were 1) research on a Cypriot population, 2) age of participants between 10 and 19 years old as suggested by the World Health Organization (WHO), ${ }^{8} 3$ ) classification of underweight (UW), overweight (OW) and obesity (OB) separately, according to the International Obesity Task Force (IOTF) criteria, ${ }^{9,10} 4$ ) weight-status classification according to sex, 5) publication of the results after 2001, when the IOTF criteria were announced, and prior to December 2010 and 6) collection of the sample between 2000 and 2010.

Studies were excluded from the analyses when they 1) reported mean/median Body Mass Index (BMI) values instead of weight-status categories, 2) diagnosed overweight/obesity with different criteria from those of the IOTF, 3) reported a combined weight status for both sexes, 4) used children aged below 10 years old in the reported prevalence, 5) consisted of overlapping studies, 6) used samples recruited from hospitals (i.e. with a possible or diagnosed pathological condition), 7) used non-healthy participants and 8) collected data prior to the year 2000.

\section{Quality of the retrieved studies and sensitivity analysis}

Specific protocol/sample characteristics for adolescent studies ${ }^{11}$ and the criteria based on the Newcastle-Ottawa Scale ${ }^{12}$ for nonrandomized research were adopted and applied in order to single out the studies of good quality. ${ }^{13}$ Studies of good quality were identified as having a sample larger than 500 adolescents, reporting a response rate greater than $70 \%$ and having weight and height measured by researchers instead of being reported by the participants. Studies that did not fulfill these criteria were considered of lower quality.

Sensitivity analyses were performed by removing the studies of lower quality in order to evaluate if the results were statistically significant compared to the total of the retrieved studies. Publication bias was evaluated by using funnel plots. Heterogeneity was determined by the $\mathrm{I}^{2}$ index and when $\mathrm{I}^{2}$ was smaller than $75 \%$, heterogeneity was considered low and subsequently a fixed model meta-analysis was performed, as suggested by Higgins and his associates. ${ }^{14}$

\section{Statistical analyses}

Several studies have used meta-analyses in order to accurately calculate the prevalence of a disease as recorded in the literature, ${ }^{13,15,16}$ and recently one study used the same methodology to accurately determine the prevalence of obesity among Greek children. ${ }^{13}$ Analyses were performed with Comprehensive MetaAnalysis software V2.0 (Biostat Inc, Englewood, NJ, USA). Significance was set at $\mathrm{p} \leq 0.05$. Differences in the prevalence of overweight and obesity between the 
two sexes were assessed with tests for two proportions (MiniTab ${ }^{\circledast}$ version 14.1 Minitab Inc., State College, PA, USA).

\section{RESULTS}

\section{Extraction process}

The performed searches retrieved a total of 31 studies but only 8 fulfilled the inclusion criteria. The flow chart of the selection process is depicted in Figure 1, carried out according to the PRISMA statement guidelines for systematic reviews and meta-analyses. ${ }^{17}$ A total of nine full-text articles were excluded for grouping both sexes together $(n=2)$, reporting mean BMI only $(n=2)$, being reviews $(n=2)$, failing to report prevalence of each weight status category $(n=2)$ and for using a children-only sample $(n=1)$.

The results concerning the weight status of Cypriot adolescents according to the selected eight crosssectional studies are presented in Table 1. Five studies involved original research published in peer review journals and three consisted of university theses. ${ }^{21-23}$ The majority of studies involved national representative samples, except for one that used a sample recruited from the city of Limassol only. ${ }^{24}$ Further details were provided by the authors of three studies in order to exclude participants aged under 10 years old $^{20}$ and in order to separate between overweight and obese adolescents. ${ }^{20,24,25}$ Only two studies determined the prevalence of underweight, ${ }^{21,25}$ a number considered inadequate for performing meta-analyses. The prevalence of underweight ranged between 3.1-5.2\% in the boys and 5.7-12.9\% in the girls. The proportion of obese adolescents exhibited great variability, ranging between $5.3-16.9 \%$ in the boys and $4.5-11.5 \%$ in the girls, whereas overweight was reported to range between $17.1-31.6 \%$ and $12.1-27.7 \%$ in boys and girls, respectively. One study used a boys-only sample. ${ }^{23}$

Only three studies fulfilled the quality criteria set for the sensitivity analyses. ${ }^{18-20}$

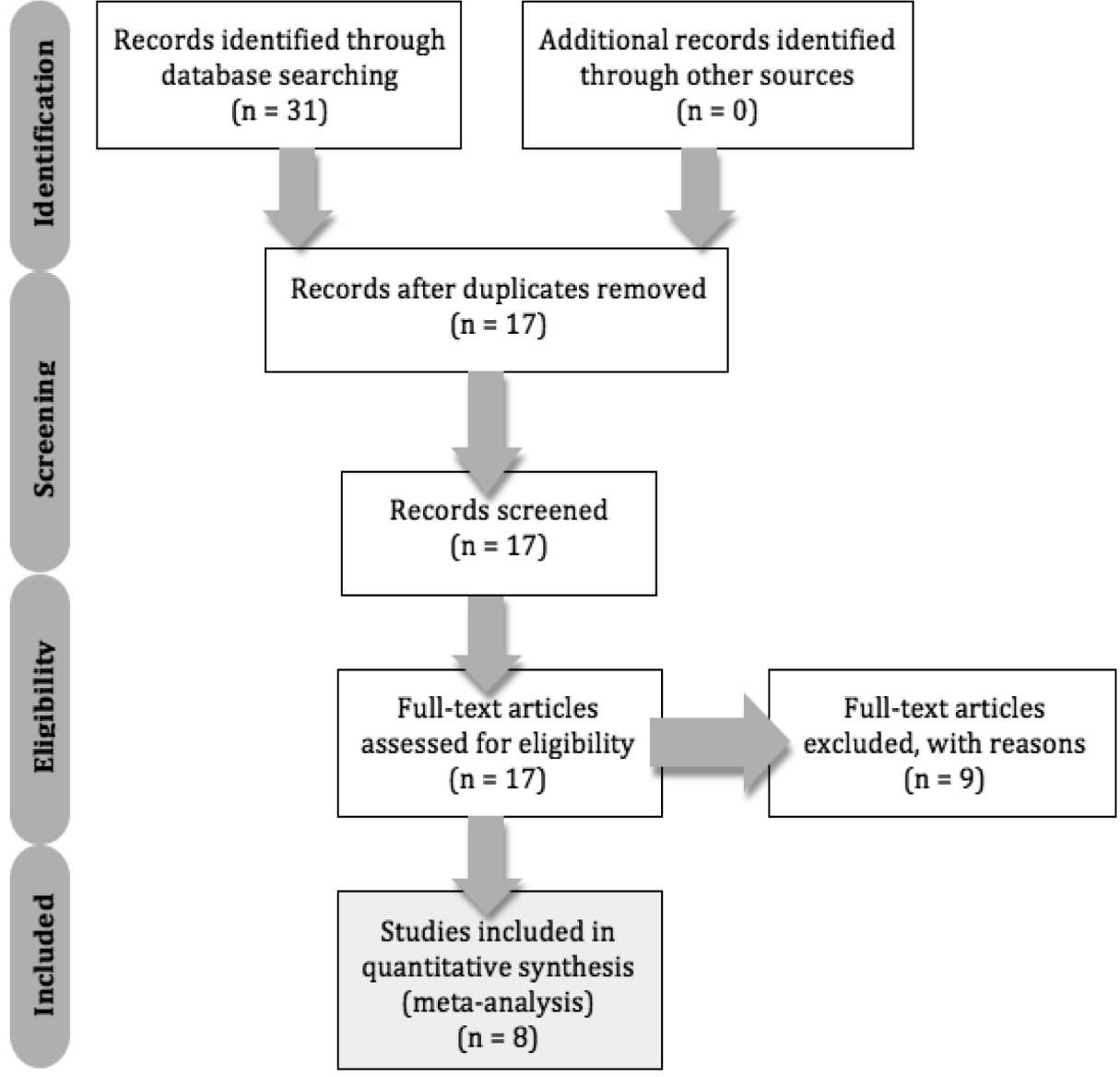

Figure 1. Flow chart of the selection of studies used in the analyses according to the PRISMA statement. ${ }^{17}$ 
Table 1. Studies assessing the weight status of Cypriot adolescents (2000-2010)

\begin{tabular}{|c|c|c|c|c|c|c|c|c|c|c|c|c|c|}
\hline \multirow{2}{*}{$\begin{array}{l}\text { Data } \\
\text { Collection } \\
\text { (year) }\end{array}$} & \multirow{2}{*}{$\begin{array}{c}\text { Study } \\
\text { Sample }\end{array}$} & \multirow[b]{2}{*}{ References } & \multirow{2}{*}{$\begin{array}{c}\text { Total } \\
\text { Sample } \\
\text { Size (n) }\end{array}$} & \multirow{2}{*}{$\begin{array}{l}\text { RR } \\
(\%)\end{array}$} & \multirow{2}{*}{$\begin{array}{c}\text { Age } \\
\text { (years) }\end{array}$} & \multicolumn{4}{|c|}{ Boys } & \multicolumn{4}{|c|}{ Girls } \\
\hline & & & & & & $\mathbf{n}$ & $\% \mathrm{UW}$ & $\% \mathrm{OW}$ & $\% \mathrm{OB}$ & $\mathbf{n}$ & $\% \mathrm{UW}$ & $\% \mathrm{OW}$ & $\% 0 \mathrm{OB}$ \\
\hline 2000 & National $^{1}$ & Savva et al ${ }^{18}$ & $2,600^{3}$ & $94.9 \%$ & $10-18$ & 835 & - & 21.3 & 7.1 & 859 & - & 16.5 & 4.5 \\
\hline 2003 & National $^{1}$ & Savva et al ${ }^{19}$ & $18,792^{3,4}$ & $75.0 \%$ & 11 & 774 & - & 21.4 & 8.8 & 751 & - & 21.8 & 7.0 \\
\hline 2005 & National $^{1}$ & Lazarou et $\mathrm{al}^{20}$ & $682^{3}$ & $91.2 \%$ & $10-14$ & 336 & - & 19.0 & 11.6 & 346 & - & 18.5 & 8.4 \\
\hline 2005 & National & Christaki $^{21}$ & 1,365 & $69.0 \%$ & 11 & 466 & 3.1 & 19.1 & 16.9 & 476 & 5.7 & 15.9 & 11.5 \\
\hline 2006 & National & Lavithi $^{22}$ & 1,500 & $56.9 \%$ & $12-17$ & 373 & - & 24.7 & 5.3 & 481 & - & 12.1 & 2.8 \\
\hline 2007 & National & Photiou $^{23}$ & $4,271^{3}$ & NR & $10-18$ & 2,954 & - & 17.1 & 13.2 & - & - & - & - \\
\hline 2007 & Limassol & Loucaides \& Jago ${ }^{24}$ & 247 & $95.5 \%$ & $10-12$ & 117 & - & 31.6 & 8.5 & 119 & - & 27.7 & 5.0 \\
\hline 2008 & National $^{2}$ & Loucaides et $\mathrm{al}^{25}$ & 1,966 & $91.6 \%$ & $12-16$ & 946 & 5.2 & 21.8 & 7.7 & 854 & 12.9 & 13.8 & 4.8 \\
\hline
\end{tabular}

${ }^{1}$ Studies used in the sensitivity analyses (quality studies), ${ }^{2}$ For the majority of the participants, weight and height were reported, not measured, ${ }^{3}$ The total sample also included participants aged below 10 years old, ${ }^{4}$ The study was cross-sectional at two time points and only the second sample, recruited after the year 2000, was used in the review. RR: Response Rate; NR: not reported; UW: underweight; OW: overweight; OB: obese.

\section{Prevalence of overweight, obesity and combined prevalence in the total sample}

In the total sample (boys and girls grouped together), $18.4 \%$ were considered overweight [95\%CI:17.6$19.2 \%, \mathrm{Q}=21.3, \mathrm{p} \leq 0.001, \mathrm{I}^{2}=67.2 \%$ ] according to the pooled analysis and $19.8 \%$ according to the sensitivity analysis [95\% CI:18.4-21.2\%, Q $=3.4, \mathrm{p} \leq 0.001$, $\left.\mathrm{I}^{2}=40.3 \%\right]$. As far as obesity is concerned, random effects models (REMs) revealed that $8.5 \%$ of adolescents in Cyprus were obese during the years 2000-2010 as calculated by the pooled analysis [95\% CI:6-11\%, $\mathrm{Q}=7.1, \mathrm{p} \leq 0.001, \mathrm{I}^{2}=1.8 \%$ ], compared to the $7.7 \%$ produced by the sensitivity analysis [95\% CI:5.5-9.9\%, $\left.\mathrm{Q}=2.2, \mathrm{p} \leq 0.001, \mathrm{I}^{2}=9.5 \%\right]$. The pooled combined prevalence of overweight and obesity was $27.8 \%$ in the total sample calculated with the use of a REM [95\% CI:25.1-30.5\%, Q =8.6, $\mathrm{p} \leq 0.001, \mathrm{I}^{2}=18.7 \%$ ] and the respective one calculated by the sensitivity analysis reached 27.1\% [95\%CI:25.4-28.7\%, Q=7.7, $\mathrm{p} \leq 0.001, \mathrm{I}^{2}=73.9 \%$ ].

\section{Prevalence of overweight in each sex}

Table 2 shows the prevalence of overweight, obesity and the combined prevalence for each sex. Both the pooled and the sensitivity analyses retrieved a similar prevalence of overweight in boys. More precisely, the pooled analysis revealed that $19.3 \%$ of adolescent boys were overweight [95\% CI:18.3-20.3\%, Q =24.3, $\left.\mathrm{p} \leq 0.001, \mathrm{I}^{2}=71.2 \%\right]$ and the sensitivity analysis produced a prevalence of $20.9 \%$ [95\%CI:18.9-20.3\%,
$\left.\mathrm{Q}=0.7, \mathrm{p} \leq 0.001, \mathrm{I}^{2}=0 \%\right]$. In girls, the pooled prevalence of overweight was calculated with a REM due to heterogeneity as indicated by $\mathrm{I}^{2}$. Thus, $17.1 \%$ of girls were considered overweight [95\% CI:14.2-20\%, $\mathrm{Q}=7.8, \mathrm{p} \leq 0.001, \mathrm{I}^{2}=23.7 \%$ ], a prevalence akin to the one produced by the sensitivity analysis of $18.6 \%$ [95\%CI:16.7-20.5\%, Q =5.8, $\mathrm{p} \leq 0.001, \mathrm{I}^{2}=65.7 \%$ ]. No statistically significant difference was observed between the prevalence of overweight calculated by the pooled and sensitivity analyses in either sex.

\section{Prevalence of obesity in each sex}

When the pooled obesity data were analyzed, the studies showed great heterogeneity $\left(\mathrm{I}^{2}>75 \%\right)$ and, subsequently, REMs were performed. The pooled calculated rate of obesity among boys was $9.8 \%$ [95\%CI:7.3-12.3\%, Q=7.4, $\left.\mathrm{p} \leq 0.001, \mathrm{I}^{2}=4.8 \%\right]$ and $6.1 \%$ among adolescent girls [95\% CI:4.2-8\%, $\mathrm{Q}=7.7$, $\left.\mathrm{p} \leq 0.001, \mathrm{I}^{2}=22.4 \%\right]$. The sensitivity analyses revealed that $8.3 \%$ of boys [95\% CI:7-9.5\%, Q $=5.2, \mathrm{p} \leq 0.001$, $\left.\mathrm{I}^{2}=61.3 \%\right]$ and $5.8 \%$ of girls [95\%CI:4.7-6.9\%, $\mathrm{Q}=7.4$, $\left.\mathrm{p} \leq 0.001, \mathrm{I}^{2}=73.1 \%\right]$, respectively, were obese during the examined time frame.

\section{Combined prevalence of overweight and obesity in each sex}

As far as the combined prevalence of overweight and obesity is concerned, the pooled produced prevalence for boys was 30.4\% [95\%CI:29.1-31.7\%, Q =8.4, $\left.\mathrm{p} \leq 0.001, \mathrm{I}^{2}=16.8 \%\right]$ and the ratio calculated by the 
Table 2. Aggregated results of the pooled and sensitivity analyses of studies assessing the prevalence of overweight and obesity in Cypriot adolescents (2000-2010)

\begin{tabular}{|c|c|c|c|c|c|c|c|c|c|c|c|c|c|c|c|c|c|}
\hline \multirow[b]{3}{*}{ Analyses } & \multirow{3}{*}{$\begin{array}{l}\text { Weight } \\
\text { Status }\end{array}$} & \multicolumn{6}{|c|}{ Boys } & \multicolumn{6}{|c|}{ Girls } & \multirow{2}{*}{$\underset{\text { between }}{p}$} & \multirow[b]{3}{*}{ OR } & \multirow{2}{*}{\multicolumn{2}{|c|}{$95 \%$ CI }} \\
\hline & & & Total & $95 \%$ & $6 \mathrm{CI}$ & & & & tal & $95 \%$ & $6 \mathrm{CI}$ & & & & & & \\
\hline & & $\%$ & $\mathbf{n}$ & Lower & Upper & Q & $I^{2}$ & $\%$ & $\mathbf{n}$ & Lower & Upper & Q & $\mathbf{I}^{2}$ & sexes & & Lower & Upper \\
\hline \multirow{3}{*}{$\begin{array}{l}\frac{0}{0} \\
\frac{0}{0} \\
\varrho\end{array}$} & Obesity & 9.8 & 6,081 & 7.3 & 12.3 & 7.4 & 4.8 & $6.1^{*}$ & 3,886 & 4.2 & 8.0 & 7.7 & 22.4 & 0.001 & 1.7 & 1.4 & 2.0 \\
\hline & Overweight & 19.3 & 6,081 & 18.3 & 20.3 & 24.3 & 71.2 & 17.1 & 3,886 & 14.2 & 20.0 & 7.8 & 23.7 & 0.001 & 1.3 & 1.2 & 1.4 \\
\hline & $\begin{array}{l}\text { Overweight } \\
\text { including } \\
\text { obesity }\end{array}$ & 30.4 & 6,081 & 29.1 & 31.7 & 8.4 & 16.8 & 23.6 & 3,886 & 19.3 & 27.9 & 6.7 & 9.8 & 0.001 & 1.5 & 1.3 & 1.6 \\
\hline \multirow{3}{*}{ 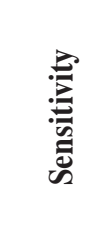 } & Obesity & 8.3 & 1,945 & 7.0 & 9.5 & 5.2 & 61.3 & 5.8 & 1,956 & 4.7 & 6.9 & 7.4 & 73.1 & 0.032 & 1.2 & 1.1 & 1.4 \\
\hline & Overweight & 20.9 & 1,945 & 18.9 & 20.3 & 0.7 & 0.0 & 18.6 & 1,956 & 16.7 & 20.5 & 5.8 & 65.7 & 0.116 & 1.1 & 1.0 & 1.3 \\
\hline & $\begin{array}{l}\text { Overweight } \\
\text { including } \\
\text { obesity }\end{array}$ & 29.5 & 1,945 & 27.1 & 31.9 & 0.7 & 0.0 & 25.4 & 1,956 & 20.1 & 20.6 & 1.6 & 0.0 & 0.001 & 1.2 & 1.1 & 1.4 \\
\hline
\end{tabular}

*Significantly different compared to the sensitivity analysis ( $\leq 0.001)$. CI: Confidence Intervals; OR: Odds Ratios for boys; Q: Cochrane's Q statistic.

sensitivity analysis reached 29.5\% [95\% CI:27.1-31.9\%, $\mathrm{Q}=0.7, \mathrm{p} \leq 0.001, \mathrm{I}^{2}=0 \%$ ]. In girls, REMs were used in the analyses and the combined prevalence of overweight and obesity was calculated as a pooled $23.6 \%$ [95\% CI:19.3-27.9\%, Q =6.7, $\mathrm{p} \leq 0.001, \mathrm{I}^{2}=9.8 \%$ ], whereas the sensitivity analysis revealed $25.4 \%$ of combined prevalence [95\% CI:20.1-20.6\%, Q $=1.6$, $\mathrm{p} \leq 0.001, \mathrm{I}^{2}=0 \%$ ].

\section{Comparisons between sexes}

Between sexes, boys demonstrated a higher prevalence of obesity and overweight ( $\mathrm{p} \leq 0.001$ for both) compared to girls. According to the pooled analysis, the odds ratio (OR) for overweight in adolescent boys compared to girls was 1.3 (CI:1.2-1.4), whereas for obesity OR was 1.7 (CI:1.4-2) ( $\mathrm{p} \leq 0.001$ for both). The boys exhibited 1.5 greater odds of being either overweight or obese during adolescence compared to girls (OR:1.5, CI:1.3-1.6). The sensitivity analyses revealed lower odds for all examined parameters (OR obesity:1.4, CI:1.1-1.8; OR overweight:1.1, CI:1-1.3; OR overweight/obesity:1.2, CI:1.1-1.4).

\section{Trend of the combined prevalence of overweight including obesity during the years 2000-2010}

Pooled cumulative analyses on the prevalence of overweight including obesity in each sex are presented in Table 3, using the eight and seven retrieved stud- ies with boys' and girls' samples, respectively. Both sexes demonstrated a slight increase apparent until the year 2005. In boys, stabilization in the prevalence of overweight/obesity was observed from the year 2005 and onwards, whereas girls experienced a slight non-linear decrease.

\section{DISCUSSION}

According to the present analyses, a total of $8.5 \%$ of Cypriot adolescents were obese during the years 2000-2010, $18.4 \%$ were overweight and $27.8 \%$ were either overweight or obese. Between sexes, $6.4 \%$ of girls and $9.8 \%$ of boys were considered obese during adolescence, whereas $17.1 \%$ and $19.3 \%$, respectively, from each sex were considered overweight. Overall, approximately $1 / 4$ of girls and $1 / 3$ of boys were either overweight or obese. Data on the prevalence of underweight are limited and research reporting the prevalence of central obesity is scarce. It is difficult to define the time point when the prevalence of adolescent overweight started rising in the island, since there are no available epidemiological studies prior to the year 2000. However, for both sexes the combined prevalence of overweight/obesity culminated during the year 2005. From then and onwards the boys stabilized their prevalence and the girls demonstrated an irregular decrease. 
Table 3. Cumulative prevalence of overweight/obesity in Cypriot adolescent boys (a) and girls (b) (2000-2010)

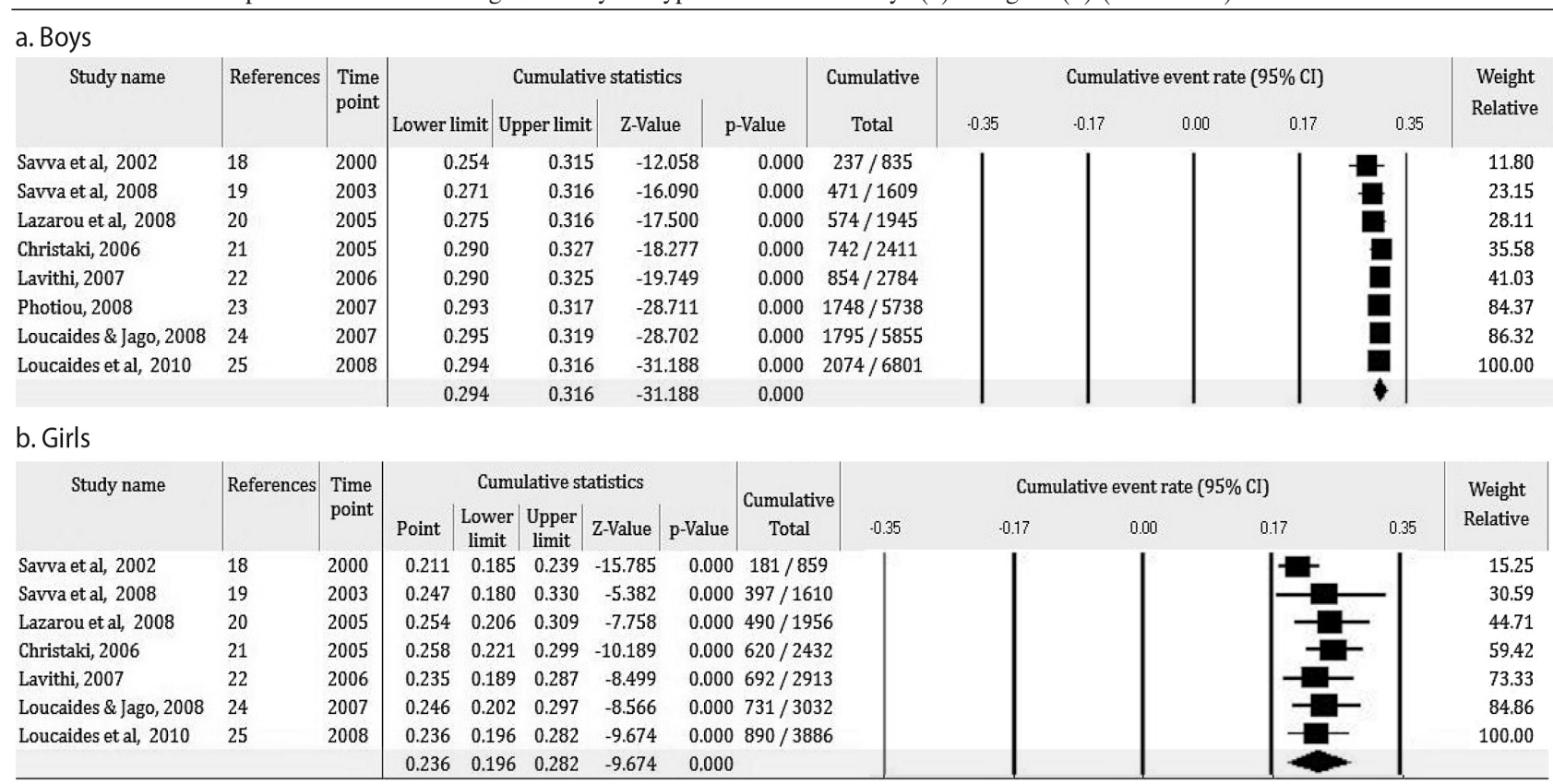

In Europe, the prevalence of childhood and adolescent overweight appears to form a gradient, with the countries situated on the lower latitudes presenting the highest rates observed. ${ }^{26}$ Cyprus is geographically situated at the lowest latitude of the continent, thus the increased rates of overweight and obesity observed in the present analysis provide further verification of the gradient theory. It has been suggested that the high prevalence of overweight observed in Southern Europe might be the result of the hot climate, as warm environments are associated with reduced thermogenesis and increased sedentary behavior due to the discomfort experienced when exercising in high temperatures. ${ }^{26}$ In confirmation of this obesogenic climate effect theory, research in Cyprus has linked childhood obesity with increased screen time and other sedentary behaviors. ${ }^{27}$

Several factors may contribute to the high prevalence of overweight, including a genetic predisposition, which is confirmed by studies on Cypriot adults, half of whom appear to be overweight/obese..$^{20}$ Unhealthy dietary choices constitute another potential explanation for the high prevalence of overweight/obesity, as the majority of Cypriot children and adolescents follow a diet of low quality. ${ }^{28}$ Additionally, bilateral parental obesity has been shown to increase the chances of offspring obesity by 18.1 times in adolescent Cypriot boys. ${ }^{18}$

Another factor contributing to the obesogenity of an environment is urbanization. ${ }^{26}$ Living in urban Cyprus has been found to affect dietary choices during adolescence, ${ }^{29}$ but data concerning the prevalence of overweight appear conflicting. Loucaides ${ }^{22}$ reported that rural Cypriot girls exercise less and Christaki ${ }^{21}$ added another finding by demonstrating higher mean BMI in rural Cypriot adolescents compared to the urban inhabitants of Larnaka and Limassol cities. Savva and his associates ${ }^{19}$ compared the relative increase in the prevalence of obesity during a 5-year period and found a substantially higher increase in rural adolescents $(35.9 \%)$ compared with those living in urban areas of Cyprus (8.7\%). However, the CYKIDS study failed to associate obesity with urbanization in school children..$^{20}$ Therefore, the exact effect of urbanization on adolescent obesity does not appear to be clear-cut, as suggested by other researchers. ${ }^{30}$ Differing definitions as to what constitutes urban/rural in each country and differences in the physical and social environment of each study's location further cloud the obesity-urbanization issue..$^{30,31}$

Today, the number of studies assessing excess in body weight according to the IOTF criteria is 
constantly increasing, ${ }^{32}$ but these do not necessarily provide quality data. Although the WHO has aptly put adolescent health in the spotlight, ${ }^{8}$ data on the prevalence of overweight/obesity during adolescence in Europe appear scattered and heterogeneous. ${ }^{32}$ This creates the need for available high-quality data objectively measuring overweight/obesity in national representative samples of European adolescents. ${ }^{32}$ In addition, the need for quality assessment of all studies assessing overweight and obesity is universal, ${ }^{26,30,32}$ as low quality studies either over- or under-estimate the actual prevalence. An example of underestimation of the prevalence of obesity is manifest in the difference observed between pooled and sensitivity analysis performed in the girls' data from the results herein. This problem can be addressed by performing systematic reviews and meta-analyses on the prevalence of overweight in each country as well as in the whole continent.

Both sexes demonstrated a slight increase in the prevalence of overweight/obesity that peaked during the year 2005. As data prior to the year 2000 do not exist, it is possible that the first studies conducted between the years 2000-2005 alarmed both the public health sector and the parents and this augmentative trend was halted. In addition, the characterization of obesity as an epidemic also took place early during the 2000's. ${ }^{33}$ These warnings produced immediate policy options for responding to the growing obesity challenge from the Cyprus Institute of Child Health ${ }^{6}$ and triggered the initiation of several communityoriented interventions aiming to promote the adoption of a healthy obesity-preventing lifestyle, like the multi-centered European IDEFICS consortium, ${ }^{5}$ or the Cypriot initiative of adopting a $15 \mathrm{~min}$ work-out every morning for school staff and pupils. ${ }^{34}$ According to the cumulative analyses, the combined prevalence of overweight and obesity ceased spiraling during the year 2005. Since then, a stabilization in prevalence has been observed among boys and a slight decrease in girls; however, the overall prevalence is still elevated and further interventions are needed in order to combat the disease. During the year 2005, the Cypriot Ministry of Health joined the European Network for Health Education in Schools and since the year 2006 structured protocols of health education, including nutrition, have been adopted adopted in schools throughout the country. Although we do not have evidence of a direct impact of these health education protocols, it is highly likely that the efforts to ameliorate nutritional knowledge and correct the lack of physical inactivity in adolescents have had an effect on halting the increasing prevalence of overweight.

The present review also identified heterogeneity in several aspects of the available data and lack of data concerning the prevalence of abdominal obesity and underweight, as reported by others. ${ }^{30,32}$ In fact, the majority of studies report mean waist circumference measurements instead of the prevalence of abdominal obesity and, as far as underweight is concerned, researchers appear to underestimate the increased prevalence observed especially in girls, and in their majority do not distinguish between underweight and normal body weight adolescents. Between pooled and sensitivity analyses, a higher proportion of adolescents were considered obese in the latter, showing a compromised accuracy in the results published by lower quality studies and adding more emphasis to the need for high quality studies to be performed. Heterogeneity was also observed in the age-range defining adolescence and this produces problems in comparing data. According to $\mathrm{WHO},{ }^{8}$ the age spectrum for adolescence ranges between 10 and 19 years; however, several researchers use convenient samples with either wider or smaller age-ranges that tend to either under- or over-estimate the actual prevalence of overweight in the adolescent population. In samples recruited from hospitals, adolescence is often defined according to the Marshall and Tanner stages, ${ }^{35,36}$ a classification often conflicting with the proposed WHO age-range.

Compendiously, the present study demonstrated high rates of overweight and obesity among Cypriot adolescents during the decade 2000-2010. Overall, this study shows that we are in need of quality studies also calculating the prevalence of underweight and abdominal obesity as such data are either missing or limited. Additionally, school-based structured nutrition and physical activity education programs including parental involvement should be continued in order to ensure a healthier adolescent and future adult population. Due to the lack of similar studies across Europe, comparisons of the present findings are not feasible. In addition, it is suggested that systematic 
reviews and meta-analyses should be performed in more European countries in order to obtain objective data on the prevalence of overweight/obesity among different age groups.

\section{REFERENCES}

1. Lobstein T, Baur L, Uauy R, 2004 Obesity in children and young people: a crisis in public health. Obes Rev 5: 4-104.

2. Fonseca H, Matos MG, Guerra A, Pedro JG, 2009 Are overweight adolescents at higher risk of engaging in unhealthy weight-control behaviours? Acta Paediatr 98: 847-852.

3. Cavazos-Rehg PA, Krauss MJ, Spitznagel EL, Schootman M, Cottler LB, Bierut LJ, 2010 Associations between multiple pregnancies and health risk behaviors among U.S. adolescents. J Adolesc Health 47: 600-603.

4. Burt Solorzano CM, McCartney CR, 2010 Obesity and the pubertal transition in girls and boys. Reproduction 140: 399-410.

5. De Henauw S, Verbestel V, Mårild S, 2011 The IDEFICS community-oriented intervention programme: a new model for childhood obesity prevention in Europe? Int J Obes (London) 35: Suppl 1: 16-23.

6. Savva SC, Chadjioannou M, Tornaritis MJ, 2007 Policy options for responding to the growing challenge from obesity: Cyprus national findings. Obes Rev 8S2: 37-45.

7. Young SS, Bang H, 2004 The file-drawer problem, revisited. Science 306: 1133-1134.

8. World Health Organization, 2002 Adolescent friendly health services. An agenda for change. [16 April 2014]: Available from: http://whqlibdoc.who.int/hq/2003/ WHO_FCH_CAH_02.14.pdf

9. Cole TJ, Bellizzi MC, Flegal KM, Dietz WH, 2000 Establishing a standard definition for child overweight and obesity worldwide: international survey. BMJ 320: 1240.

10. Cole TJ, Flegal KM, Nicholls D, Jackson AA, 2007 Body mass index cut offs to define thinness in children and adolescents: international survey. BMJ 335: 194-202.

11. Lien N, Henriksen HB, Nymoen LL, Wind M, Klepp KI, 2010 Availability of data assessing the prevalence and trends of overweight and obesity among European adolescents. Public Health Nutr 13: 1680-1687.

12. Wells GA, Shea B, O'Connell D, et al, The NewcastleOttawa Scale (NOS) for assessing the quality of nonrandomized studies in meta-analyses. [16 April 2014]: Available from: http://www.ohri.ca/programs/clinical_epidemiology/oxford.htm

13. Kotanidou EP, Grammatikopoulou MG, Spiliotis BE, Kanaka-Gantenbein C, Tsigga M, Galli-Tsinopoulou A, 2013 Ten-Year obesity and overweight prevalence in Greek children: A systematic review and meta-analysis of 2001-2010 data. Hormones (Athens) 12: 537-549.

14. Higgins JPT, Thompson SG, Deeks JJ, Altman DG,
2003 Measuring inconsistency in meta-analyses. BMJ 327: 557-560.

15. Chen JJ, Yu CB, Du WB, Li LJ, 2011 Prevalence of hepatitis $\mathrm{B}$ and $\mathrm{C}$ in HIV-infected patients: a meta-analysis. Hepatobiliary Pancreat Dis Int 10: 122-127.

16. Tsigga M, Grammatikopoulou MG, 2012 Assessing the silent epidemic of malnutrition in Palestinian preschool children. J Epidemiol Glob Health 2: 181-191.

17. Moher D, Liberati A, Tetzlaff J, Altman DG, The PRISMA Group, 2009 Preferred Reporting Items for Systematic Reviews and Meta-Analyses: The PRISMA Statement. PLoS Med 6: e1000097.

18. Savva SC, Kourides Y, Tornaritis M, Epiphaniou-Savva M, Chadjigeorgiou C, Kafatos A, 2002 Obesity in children and adolescents in Cyprus. Prevalence and predisposing factors. Int J Obes Relat Metab Disord 26: 1036-1045.

19. Savva SC, Tornaritis MJ, Chadjigeorgiou C, Kourides YA, Siamounki M, Kafatos A, 2008 Prevalence of overweight and obesity among 11-year-old children in Cyprus, 1997-2003. Int J Pediatr Obes 3: 186-192.

20. Lazarou C, Panagiotakos DB, Panayiotou G, Matalas AL, 2008 Overweight and obesity in preadolescent children and their parents in Cyprus: prevalence and associated socio-demographic factors - the CYKIDS study. Obes Rev 9: 185-193.

21. Christaki M, 2006 Correlation between childhood obesity and overweight with possible predisposing factors in a Cypriot sample of 11 year-olds. MSc Thesis, Harokopio University, Athens, Greece. http://estia.hua.gr:8080/ dspace/bitstream/123456789/98/1/Metaptychiaki21.pdf

22. Lavithi D, 2007 Assessment of the dietary habits of adolescents aged 12-17 years old from Cyprus. MSc Thesis, Harokopio University, Athens, Greece. http://estia.hua. gr:8080/dspace/bitstream/123456789/368/1/lavithi.pdf

23. Photiou A, 2008 Somatic development and body composition of 6- to 18-year-old boys - The first Cypriot growth study. PhD Thesis, Semmelweis University, Budapest, Hungary.

24. Loucaides CA, Jago R, 2008 Differences in physical activity by gender, weight status and travel mode to school in Cypriot children. Prev Med 47: 107-111.

25. Loucaides CA, Jago R, Theophanous M, 2010 Prevalence and correlates of active travelling to school among adolescents in Cyprus. Cent Eur J Public Health 18: 151-156.

26. Lobstein T, Frelut M-L, 2003 Prevalence of overweight among children in Europe. Obes Rev 4: 195-200.

27. Lazarou C, Soteriades ES, 2010 Children's physical activity, TV watching and obesity in Cyprus: the CYKIDS study. Eur J Public Health 20: 70-77.

28. Lazarou C, Panagiotakos DB, Kouta C, Matalas AL, 2009 Dietary and other lifestyle characteristics of Cypriot school children: results from the nationwide CYKIDS study. BMC Public Health 9: 147.

29. Lazarou C, Kalavana T, 2009 Urbanization influences dietary habits of Cypriot children: the CYKIDS study. 
Int J Public Health 54: 69-77.

30. Mirkopoulou D, Grammatikopoulou MG, Gerothanasi K, Tagka A, Stylianou C, Hassapidou M, 2010 Metabolic indices, energy and macronutrient intake according to weight status in a rural sample of 17-year-old adolescents. Rural Remote Health 10: 1513.

31. Hodgkin E, Hamlin MJ, Ross JJ, Peters F, 2010 Obesity, energy intake and physical activity in rural and urban New Zealand children. Rural Remote Health 10: 1336.

32. Lien N, Henriksen HB, Nymoen LL, Wind M, Klepp KI, 2010 Availability of data assessing the prevalence and trends of overweight and obesity among European adolescents. Public Health Nutr 13: 1680-1687.

33. James PT, Leach R, Kalamara E, Shayeghi M, 2001 The Worldwide Obesity Epidemic. Obes Res 9: Suppl 4: 228-233.

34. Lobstein T, 2006 Comment: Preventing child obesity an art and a science. Obes Rev 7: 1-5.

35. Marshall WA, Tanner JM, 1969 Variations in pattern of pubertal changes in girls. Arch Dis Child 44: 291-303.

36. Marshall WA, Tanner JM, 1970 Variations in pattern of pubertal changes in boys. Arch Dis Child 45: 13-23. 